\title{
BIOTECHNOLOGY
}

\section{AMERICAN BIOTECHNOLOGY NEEDS A STRATEGIC PLANNING CENTER}

7 he United States has vet to form a consistent set of policies which addresses both the problems and the economic potential of biotechnology. Despite the fact that federal money continues to
upport excellent research, and that corporations have begun manufacturing the first generation of genetically engineered products, biotechnology has not enjoyed the critical attention it deserves from legislators and the general public which elects its representatives. It has not been applauded as one of the key factors for technological innovation over the next 30 years. This is a serious mistake.

Until now, public and bureaucratic attention have focused more on the regulatory side of biotechnology at the expense of its research and industrial potential. There is grave danger that the more dramatic, fear-provoking sentiments about the unknown will prevail. Evidence of this can be found in recent activities by Rep. Albert Gore's (I) - I'N) Subcommittee on Investigations and Oversight of the House Science and Technology Committee. Gore, whose panel has carefully examined issues of ethics, technology transfer, and university-industrial relations, may soon propose formation of an oversight committee to examine biotechnology's development. The President's Commission for the Study of Ethical Problems in Medicine provided another sign of official concern about biotechnology last fall, recommending that an oversight group be established to suggest direction for genetic technologies which affect humans. This committee, like one of Gore's proposed committees, would be composed largely of laymen.

It would be an error for the industrial biotechnology community to remain idle while government officials propose oversight committees to regulate and control the direction of $\mathrm{R} \& \mathrm{I}$. And it would be unfortunate to allow the Recombinant DNA Advisory Committee (RAC) to expand into areas beyond its scope, developing detailed regulatory policies for manufacturing or for release of products into the environment. Seated within the National Institutes of Health, the RAC has neither the industrial expertise nor the appropriate position in the government to form policies affecting the spectrum of bioresearch.

lhe overall direction of biotechnology's development, including its regulation, must fit within a strategy of longterm national economic development. This strategy and its accompanying policies should be directed by experts in science, technology, and finance, not by lay panels which may not appreciate the many potential benefits of this form of industrial innovation. Although discussion proceeds about the appropriate place in government for an oversight body, no unified voice can be heard about how the economic and technical benefits of biotechnology can be happily married on a long-term basis.

Now is the time when biotechnology development policies are open to formulation. The Office of Technology Assessment will soon deliver to Congress the first official analysis devoted exclusively to commercialization of biotechnology. This could be the first opportunity for supporting biotech R\&D on a long-term, market-oriented basis through tax incentives, new grant-giving policies, and other vehicles.

A permanent body should be formed to analyze the problems and opportunities without the compulsion to either regulate or lobby for any particular interest group. If this proposed Biotechnology Strategic Planning Commission is to be located within the government, its rightful place should be within a well-established committee which seeks economic expansion through technology development. If it exists outside the government, it could reside within a new, philanthropic foundation in the tradition of such diverse entities as the Battelle Memorial Institute, MIT, and other prominent pro-technology institutions. It could also find a more modest but productive home within one of the larger scientific and technological societies, or it could be established within an existing think tank through a long-term commitment of government funding. Support of this commission must come eventually from all sources affected by biotechnology's future-trade associations, corporations, and government officials who represent tomorrow's consumers of new research-based products.

Over the next two decades American biotechnology will face competition from Japan, France, and other foreign competitors which benefit from centralized government planning and incentives to stimulate R\&D. An American strategy to ensure a dominant role in biotechnology's future should be formed immediately.

An independent planning commission which champions the cause of integrated development would help set biotechnology as a national priority, providing the necessary body of intelligence from which regulatory, legislative, corporate, and public leaders could draw. - Christopher Edwards

\section{INVITATION TO READERS}

7 he publication of this ambitious magazine/journal of industrial biology is similar in some respects to successful research and development projects in biotechnology. The seemingly endless planning, negotiating, hiring, and arduous work prior to the birth of $\mathrm{BIO} / \mathrm{TECHNOL}$ OGY were conducted in parallel with a careful testing of our market to determine our readers' information needs. We believe that the result, beginning with this issue, should enhance the quality of industrial and academic: biotechnology. We are particularly proud to feature the fastest peer review system in journal publishing.

We intend to help close the gap between the basic researcher, the applications engineer, and the marketing expert. But in order for us to do this, we will rely very heavily upon your comments. Your letters, reports, and critical thoughts are necessary in our efforts to contribute to industrial innovation through biotechnology. 